This item was submitted to Loughborough's Research Repository by the author.

Items in Figshare are protected by copyright, with all rights reserved, unless otherwise indicated.

\title{
Investigating undergraduate mathematics learners' cognitive engagement with recorded lecture videos
}

PLEASE CITE THE PUBLISHED VERSION

https://doi.org/10.1080/0020739X.2018.1458339

\section{PUBLISHER}

(c) Taylor \& Francis

\section{VERSION}

AM (Accepted Manuscript)

\section{PUBLISHER STATEMENT}

This work is made available according to the conditions of the Creative Commons Attribution-NonCommercialNoDerivatives 4.0 International (CC BY-NC-ND 4.0) licence. Full details of this licence are available at: https://creativecommons.org/licenses/by-nc-nd/4.0/

\section{LICENCE}

CC BY-NC-ND 4.0

\section{REPOSITORY RECORD}

Trenholm, Sven, B. Hajek, Carol L. Robinson, M. Chinnappan, A. Albrecht, and H. Ashman. 2019. “Investigating Undergraduate Mathematics Learners' Cognitive Engagement with Recorded Lecture Videos". figshare. https://hdl.handle.net/2134/32652. 


\title{
Investigating Undergraduate Mathematics Learners’ Cognitive Engagement with Recorded Lecture Videos
}

\begin{abstract}
:
The use of recorded lecture videos (RLVs) in mathematics instruction continues to advance. Prior research at the post-secondary level has indicated a tendency for RLV use in mathematics to be negatively correlated with academic performance, though it is unclear whether this is because regular users are generally weaker mathematics students or because RLV use is somehow depressing student learning. Through the lens of cognitive engagement, a quasiexperimental pre- and post-test design study was conducted to investigate the latter possibility.

Cognitive engagement was operationalised using the Revised Two-Factor Study Process Questionnaire (R-SPQ-2F), which measures learning approaches on two major scales: surface and deep. In two mathematics courses at two universities, in Australia and the UK, participants were administered the questionnaire near the course start and finish. Overall findings were similar in both contexts: a reduction in live lecture attendance coupled with a dependence on RLVs was associated with an increase in surface approaches to learning.
\end{abstract}

This study has important implications for future pedagogical development and adds to the sense of urgency regarding research into best practices using RLVs in mathematics.

Keyword: online learning, lecture, recorded video, engagement, approaches to studying, approaches to learning

\section{Introduction}

Higher education is changing rapidly. Perhaps no change is more fundamental than with regards to lecture delivery where, mirroring increasing student demand [1], the adoption of recorded lecture videos (RLVs) continues to expand [2]. In Australia, for example, almost half of the top-20 ranked universities in 2013 [3] had institution-wide opt-out policy initiatives. This is where all live (i.e. face-to-face) lectures are recorded for later viewing unless the instructor chooses otherwise. Other universities have similar plans or current policies at the school or faculty level [4].

Often linked with names such as blended or flipped learning, recorded videos may be as varied as short staged PowerPoint presentations with voiceovers covering specific concepts [e.g., "screencasts": see, for example, 5] to basic recordings of the lecturer giving a lecture [e.g., "lecture capture": see, for example, 6]. The focus of this study is on the more common institutional practice of recording the face-to-face lecture given on campus for later use [7], and made accessible via the university’s online learning management system.

\section{General Background}

Reflecting initial concerns, early general research focused on the effect of RLV use on: (a) lecture attendance - with most studies finding little to no effect [6,8-10]; (b) academic performance - with most concluding either no negative effects [11,12] or some positive effects [13-17] and few finding a negative impact [18]; and (c) student satisfaction with increased student satisfaction as one of the most consistent findings and, arguably, one of the principal drivers of current implementation efforts [6,19,20].

Little remains known, however, about the nature of learner engagement ${ }^{1}$ with recorded lectures [20-23]. Previous research commonly reports on the nature of mostly behavioural engagement over the duration of a course (e.g., student RLV “click” data). For example, investigations of video usage suggest, not surprisingly, that students tend to use these videos more often around the time of major assessments [12,24,25]. Though interesting, this macro level analysis does not tell us anything about the nature of learner engagement at the more micro level. For example, how do students engage with single RLVs, particularly in relation to the quality of their learning? Fuelled, at least in part, by the availability of new sources of data, other emerging research is attempting to do this by, for example, investigating student use of video functions, such as video annotation, in relation to student learning. For example, in the context of a health sciences course, Chiu, Chen, Huang et al. [26] used eye-tracking technology to investigate

\footnotetext{
${ }^{1}$ Though "student engagement" tends to be the preferred term used in the research literature, the term "learner engagement" is used in this paper in an effort to forefront the primary process and desired outcome of engagement.
} 
whether the use of video annotations helped improve student learning. They found this functionality has the potential to improve learning performance vs. the more conventional use of RLVs. Still, such research remains emergent and there remains considerable scope for investigating learner engagement with RLVs. We argue this is particularly the case in relation to the nature of the subject being taught and how it is learned [see also 27].

\section{Mathematics-specific Background}

In mathematics, the transformation surrounding lecture delivery and need for research has not been dissimilar [23, 28], though the motivation and needs may be different. For example, in the context of increasing demand but declining enrolment and standards [29], a significant number of students taking undergraduate mathematics service courses at Australian universities are considered to be struggling [30: with estimates of about $25 \%$ of students failing their first course]. To address this challenge one significant emerging effort is "flipping"” the instructional process (e.g., http://flipcurric.edu.au/). Within this approach RLVs generally become a central required component of mathematics instruction: Students are expected to use them as they prepare for their lectures/tutorials where this new knowledge is applied in, for example, problem-solving contexts [31]. Elsewhere, RLVs may simply be a resource provided alongside traditional undergraduate mathematics instruction. In this context early research suggests students tend to be either dependent on RLVs or face-to-face lectures but do not typically blend use of both [32]. In sum, whether it is as a required part of the instruction or as an optional resource, there appears to be a growing reliance on RLV use in mathematics.

Yet contrasting with these developments there is a dearth of research on how students learn mathematics with $\mathrm{RLVs}^{3}$. Indeed, perhaps more concerning, a recent review of research on RLV use in undergraduate mathematics found an overall negative correlation between RLV use and academic performance [23]. Of course it may simply be that weaker students tend to use RLVs more than other students. But, alternatively, it may also be that RLV use is somehow depressing student learning [33]. Relatedly, with the use of RLVs in mathematics instruction, only one study was found investigating this potential effect: Le, Joordens, Chrysostomou et al. [20] investigated how students' approaches to learning in a Calculus course were related to their use of pause and seek features when viewing RLVs. In relation to the nature of mathematical knowledge, they were interested in understanding how students were using lecture videos to help them learn. In one of two experiments they conducted, 64 students were surveyed at the end of the course using the Revised Two-Factor Study Process Questionnaire [R-SPQ-2F; 34] along with specific questions about the nature of their engagement with their lecture videos, including their use of pause and seek features. They found that students using more surface approaches to learning, as measured by the R-SPQ-2F, tended to use the pause feature more often. They hypothesized that some students use the RLVs, and specifically the pause button, to "memorize course content, leading to poorer performance in the course". Their research, however, relied on selfreported data of RLV use and did not measure any potential changes in study approaches, but primarily the relationship between RLV function use and end of course R-SPQ-2F measures.

\section{Theoretical Background}

This study uses the analytical lens of engagement and, more specifically, cognitive engagement. The study of student learner engagement with mathematics is considered to be a growing area in mathematics education research [35,36]. This increased interest follows claims that the quality of engagement has a "profound effect on learning outcomes" [39, p.133] and empirical evidence that engagement, by some measures, benefits student academic achievement [40].

But what is "engagement”? In previous research, when treated as a single construct, it has been considered to be both poorly defined and under-theorized [35,41]. This study adopts the definition of engagement as "the quantity and quality of mental resources directed at an object and the emotions and behaviours entailed" [italics added for emphasis; 41, p.86]. Furthermore, according to what the strongest empirical and theoretical evidence suggests [42], engagement is considered to be composed of three sub-constructs: behavioural, emotional and cognitive engagement.

As a multidimensional construct, engagement is not simply seen to be the sum of its parts but, as a whole, the product of the complex interactivity of its sub-constructs [43]. As Helme and Clarke [39, p. 33] write in the mathematics

\footnotetext{
${ }^{2}$ Flipped learning may be considered a digital technology-enabled pedagogical innovation that essentially makes the lecture, as a recorded video, the "homework" while lecture/tutorial time is used to actively work on problems traditionally given as homework. One particular approach, "whiteboard tutorials", has generated much interest both nationally and internationally [37].

${ }^{3}$ This need mirrors that of research into flipped learning in mathematics where, as an overall pedagogical approach, actual effects on student learning are considered understudied [38].
} 
education literature, these sub-constructs "support and complement each other in a synergistic manner", together interacting with pre-existing learner characteristics and the learning context to affect learning strategies and outcomes. As further discussed in the next section, and as more evidence of this complexity, motivation and self-regulation are two psychological constructs often associated with the dynamics in and around engagement [44]. Moreover, the nature of engagement should be seen as more than a quantity measure. For example, active engagement in course content, or what may be construed as the duration and intensity of engagement [45], should not be the primary goal of instruction since it is the quality of that engagement which is considered to have the most profound effect on learning [39]. This point will be returned to later in the paper.

This study focuses on one sub-construct of engagement: cognitive engagement. In the general education literature, Fredricks and McColskey [42, p. 762] define cognitive engagement as the "student's level of investment in learning [which] includes being thoughtful, strategic, and willing to exert the necessary effort for comprehension of complex ideas or mastery of difficult skills". In the mathematics education literature, this is similar to Skilling, Bobis, Martin et al.’s [45, p. 3] definition of cognitive engagement as "the extent to which students seek deep meaning and understanding as well as the cognitive strategies students use to self-regulate their learning”. As both of these definitions suggest, cognitive engagement has both quantitative and qualitative attributes which take part in what Watt and Goos [36] loosely describe as an "inside-out" dynamic. In this respect, one may take the view that the process of learning involves learners developing internal dispositions that characterize their cognitive engagement, and which are directed at the object of their study. Moreover, these dispositions are further shaped by predispositions brought to the learning process as well as other contextual factors [36]. In its finality, this dynamic is seen to help determine the nature of student learning outcomes.

\section{Research on Engagement}

Though research into learner engagement, in general, is considered to be growing, specific research focused on student cognitive engagement in mathematics appears limited. For example, a recent (May 24, 2017) Google scholar search, with "cognitive engagement" and "mathematics" in the title, yields only 16 results. Of those papers in the mathematics education literature, Helmes and Clarkes [39] is the most cited (with 100 citations). They provide some useful background in their paper and summarize the literature by stating that researchers generally agree that cognitive engagement "involves the thinking that students do while engaged in academic learning tasks" [p. 135], while they themselves define cognitive engagement as "the deliberate task-specific thinking that a student undertakes while participating in a classroom activity” [p. 136]. Other papers include, Skilling and Styliandes [46] work investigating primary teacher beliefs and practices in relation to how they promote cognitive engagement in their classes. They found equal numbers of teachers believed in and espoused contrasting approaches. Finally, in the general education literature, Archambault, Janosz and Chouinard [47] investigated how secondary teachers' beliefs predicted student cognitive engagement and achievement in mathematics. Consistent with prior issues that have been raised, they do not define cognitive engagement. However, perhaps more interestingly, they operationalize cognitive engagement using a psychometric instrument that measured the "time and effort students were ready to invest in mathematicsrelated activities” [p. 322]. That is, a quantitative, rather than qualitative, conceptualization of engagement. They found, perhaps unsurprisingly, that teachers' beliefs, expectations and self-efficacy influenced students' cognitive engagement and achievement.

Indeed, even more pressing, mathematics education research investigating the use of digital technology tools in relation to general learner engagement [35] and associated learning processes is considered to be particularly needy. This is particularly the case at the tertiary level [48]. For example, in the recent Mathematics Education Research Group of Australasia (MERGA) quadrennial review, only one related study was found in the four years covered by the review. This was a study investigating the effect of iPad use on learner engagement in primary education [49]. Further exacerbating the need for this research is the steady advance of technology and its use in education ${ }^{4}$.

Where most prior related RLV research tends to be focused on behavioural engagement (e.g., focusing on log file data analysis), the present study sets out to investigate undergraduate students' cognitive engagement with RLVs accessible online through the university’s learning management system. Specifically, in consideration of Le et al.’s [20]

\footnotetext{
${ }^{4}$ It is noted that Le et al.'s [20] study could be classified as tertiary level research into students' cognitive engagement with digital technology resources. Though, consistent with issues previously discussed, it is not specifically framed in the broader engagement literature.
} 
hypothesis, previously discussed, this study investigates how regular learner engagement with RLVs in mathematics affects students' cognitive engagement in their efforts to learn mathematics.

\section{Operationalization of Cognitive Engagement}

For the purposes of this research, cognitive engagement is defined using Skilling et al.'s [45] definition stated above. We further operationalize cognitive engagement using the Revised Two-Factor Study Process Questionnaire [R-SPQ2F; 34], the same instrument used by Le et al. [20], to evaluate the learning approaches of students. Approaches to learning is a construct considered to be closely related to cognitive engagement [50] and also found to be related to the quality of learning outcomes [51,52].

Inspired by Marton and Säljö's [53,54] early work, which considers learning on a continuum from surface (e.g., memorising concepts) to deep (e.g., flexibly linking concepts), the R-SPQ-2F is a 20 question-item instrument created to evaluate the learning approaches of students on two major scales, surface (SA for "surface approach") and deep (DA for “deep approach”), and two subscales, intention (or motivation) and strategy. As Le et al. [20, p. 317] summarize:

"The surface approach is based on extrinsic motivation, where the goal is to avoid failure with minimum time and effort, leading to rote learning. A student who takes a surface approach focuses on the concrete aspects of tasks, rather than their meaning. The deep approach is based on intrinsic motivation, where the goal is to maximize understanding. A student who adopts a deep approach focuses on the meaning of the task [55]. As the names suggest, the subscales refer to the extrinsic or intrinsic motivation, and the strategies that reflect the surface and deep approach.”

Despite some critique [56], the R-SPQ-2F has been fairly well received, having been used in numerous studies [e.g., online learning context: 57], including in mathematics education [58,59]. Furthermore, the framework appears well aligned with current theorizations about the nature of mathematical knowledge [e.g., procedural vs. conceptual, superficial vs. deep; see 60].

Of interest to this study it is noted that while students may view their learning approaches as an effective means to help advance their learning, this may often be "at odds with reality" [61, p. 423], producing little [40] or even the opposite [62] of the desired effect. Indeed, with the use of digital technology in higher education, the contrast between the potential and actual effect on learning is considered well known [63]. And, more pointedly in the context of this study, it is possible the use of RLVs may be detrimental to at least some student learning. This is despite student satisfaction with the provision of RLVs being almost consistently positive $[6,19,20]$ as well as any perception of teachers/instructional designers that RLV provision is beneficial because they provide an additional avenue for learner engagement with course content (i.e. a greater quantity of engagement). While acknowledging its concomitant influence on the nature of learning outcomes, this study sets out to discover how the use of RLVs helps and/or hinders students' approaches to learning.

Using the R-SPQ-2F questionnaire we seek to answer how low vs. regular learner engagement with RLVs in mathematics affect students' approaches to their learning of mathematics.

\section{Material and Methods}

To investigate the effect of RLVs, a quasi-experimental pre- and post-test design study was conducted focusing on measuring changes in students' cognitive engagement as operationalised using the aforementioned instrument. The study was conducted in two phases at two universities: First, in one single undergraduate mathematics course at the University of South Australia (Australia). Second, in one single, and similar, mathematics course at Loughborough University (UK). We now detail these two contexts as well as the data collection procedures. We then conclude with comments on the research method used in this study. 


\section{Study Contexts}

\section{Australia}

The context for this study was a mathematics course for engineers taking place July - November 2015, entitled “Mathematical Methods for Engineers 2". This is a required first year course for engineering degrees (electrical, civil, mechanical, mechatronics) which covers the following areas of mathematics: linear algebra, systems of first order ordinary differential equations, differential equations, and techniques and applications of integration. This course would require background understanding in, for example, Calculus 1 and prepare students for courses in, for example, topics in Calculus 3. The course included 26 lectures lasting approximately two hours each and, apart from available peer interactions, there were some limited opportunities to interact with the lecturer during the lecture (e.g., asking questions or answering questions posed by the lecturer). After each face-to-face lecture was completed the associated RLV was uploaded on the course website for student use, which allowed for automatic tracking of individual student's views ${ }^{5}$. The RLV comprised of an audio recording of the lecture, together with the projection face-to-face students would see on the overhead screen, with this projection alternating between slides containing the same material students would have in their printed lecture notes and a document camera of the lecturer working through examples. In addition to the lecture, students attended weekly one hour tutorials and fortnightly one hour computer "practicals", with this attendance manually recorded by the lecturer/tutor. Course assessment consisted of one continuous assessment (20\%), one project (15\%) and one final exam (65\%). The lecturer had a PhD in Applied Mathematics and more than 10 years of experience teaching this subject matter.

\section{$U K$}

The context for this study was a mathematics course (referred to as "module" in the UK) for engineers taking place October 2016 - January 2017, entitled "Engineering Mathematics 3". This is a required second year course as well as the third and final mathematics course for Aeronautical and Automotive engineering degrees. The course covers the following areas of mathematics: Fourier series, eigenvalues/eigenvectors, multiple integration, Vector Field Theory and Divergence and Stokes' Theorems. This course would require background understanding in, for example, Calculus 3 and prepare students for courses in, for example, fluid mechanics and aerodynamics. The course consisted of 24 lectures lasting approximately one hour each and, apart from available peer interactions, there were some limited opportunities to interact with the lecturer during the lecture (e.g., asking questions or answering questions posed by the lecturer). After each live lecture was completed the associated RLV was uploaded on the course website for student use, which allowed for automatic tracking of individual student's students' views. The RLV comprised of an audio recording of the lecture, together with the projection live students would see on the overhead screen, with this projection alternating between slides containing the same material students would have in their course workbooks and a document camera of the lecturer working through examples. In addition to the lecture, students attended 11 weekly tutorials lasting approximately one hour each, with this attendance manually recorded by the lecturer/tutor. Course assessment consisted of two multiple choice in-class tests (10\% each) and one final exam (80\%). The lecturer had a $\mathrm{PhD}$ in Applied Mathematics with more than 25 years of experience teaching this subject matter and several awards for her teaching.

\section{Data Collection Procedures}

\section{Australia}

The pre-test was administered in the first lecture of the course (Week 1) and consisted of four parts (see appendix for parts two and three): (i) Participant information sheet together with a consent form, (ii) 20-item R-SPQ-2F questionnaire, (iii) two questions interrogating students' prior general and mathematics-specific use of RLVs, and (iv) a 32 question-item grade 9 non-calculator numeracy test taken from the Australian government's NAPLAN sample test bank (https://www.nap.edu.au/naplan/the-tests).

\footnotetext{
${ }^{5}$ The university video management system provided "click data” with a time stamp for the start of video viewing. The length of time spent viewing individual videos is not provided by the video management system and therefore not accounted for in this study. Though it is possible students merely accessed but did not actually view videos, this is not suggested by student self-report data solicited in the post-test questions which, as will be reported later in the results, is consistent with available click data.
} 
The post-test was administered after the $24^{\text {th }}$ lecture (Week 12) and consisted of two parts (see appendix): (i) 20-item R-SPQ-2F questionnaire, (ii) six questions interrogating students' use of RLVs in the present course, focussing on the use of the pause and seek buttons (two questions) as well as face-to-face lectures and RLVs (four questions).

While the official course enrolment was 124 students, in the pre-test phase, 60 students consented to participating and completed the questionnaire. In the post-test phase, of 34 students completing the questionnaire, 30 had consented and completed both pre-and post-test questionnaires. University human ethics approval was sought and received for conducting this study.

\section{$U K$}

The pre-test was administered in the first tutorial (Week 2) of the course and, apart from a participant information sheet together with a consent form, consisted of only the 20-item R-SPQ-2F questionnaire. The two questions about students' prior general and mathematics-specific use of RLVs and the numeracy test were omitted mainly due to timing issues. The post-test was administered the final week (Week 11) of the course, which was before the Christmas break and the final exam. This was the same test given to participants in the Australian study.

While the official course enrolment was 166 students, in the pre-test phase, 94 students consented to participating and completed the questionnaire. In the post-test phase, of 97 students completing the questionnaire, 63 had consented and completed both pre-and post-test questionnaires. University human ethics approval was also sought and received for conducting this study.

The R-SPQ-2F measures are then calculated by summing the individual item Likert-scale measures (i.e. 1 to 5) for each subscale and then, overall, for the major scales [see 34, p. 149]. Conceptually, in this pre- and post-test design, "improved" approaches to learning may translate to a lowering of surface measures and/or an increase of deep measures of approaches to learning, with "declining” considered to be the opposite effects.

\section{Comment on the Research Method}

Controlled experiments provide an opportunity for researchers to study the effects of selected variables while controlling for others, thus allowing for causal inferences. Yet such research approaches may be difficult to undertake in certain settings. For example, in relation to the present investigation there are no known controlled experiments investigating the use of RLVs in undergraduate mathematics [23]. Moreover, while controlled laboratory experiments may yield high internal validity, for research on RLV use, there may be threats to external validity due to the use of non-naturalistic study settings. Conversely, the quasi-experimental research approach used in this study is considered to yield high external validity while also producing threats to internal validity due to, for example, the inability to control environmental factors around RLV use.

In this study, we trade-off strengths and weaknesses while attempting to deal with potential threats to validity. One strength is that students have the ability to naturally choose to attend (or not) live lectures and view (or not) RLVs in the learning environment of their choice (e.g., café, library, bedroom...). Yet with this strength comes one weakness which we acknowledge as a possible limitation to our study. That is, we know little about these environments, particularly where RLVs may be used, and thus their potential influence on any outcome measures. Some research suggests, for example, that the mere presence of a mobile may negatively affect learning [66]. If students have mobiles turned off and out of view in live lectures but on and in view when using RLVs, what effect does this have on their learning? Though we do not eliminate this threat in the present study, we contend our research is strengthened by the inclusion of other measures. We detail these measures in the next section which covers the results of our study. We also return to this discussion later in the paper.

\section{Results}

For both phases, the analysis began with standard normality and reliability tests run on all measures. While normality tests directed the choice of analysis procedures, Cronbach's alpha suggested all R-SPQ-2F subscale measures had acceptable to good reliability [64].

Next, for each phase, the analysis was conducted in two stages: First, descriptive statistics were provided along with results of a correlational analysis of RLV use in relation to academic performance. Second, following an artificial 
grouping of the data to identify low vs. regular RLV users, paired t-tests were run to investigate differences in pre-and post-test measures.

The results for each phase of the study are now reported on.

\section{Phase 1: Australian Study}

Students' $(n=30)$ total RLV views, ranging from 0 to 77 views per student, are displayed in Figure 1, with an individual student's total view count as the total number of times they accessed RLVs over the course of the semester. Consistent with prior research, a significant negative correlation between final course grade and RLV views ( $\rho=$ $0.443, \mathrm{p}=0.014$ ) was found.

$<$ Figure 1 about here>

Australian students’ approaches to learning: low vs. regular RLV users

First, those not using or only occasionally using RLVs (hereafter referred to as "low" users) were separated from those more regularly or heavily using the videos (hereafter referred to as "regular" users) by splitting the median. This is argued to be an appropriate method for three reasons: First, given the shape of the data, which was heavily skewed to the left, splitting the median permitted the artificial categorisation of those students never or rarely using RLVs as those students found in the first two quartiles, then compare this group to the remaining students who appeared to be regular or heavy users of the videos [65]. Second, and more importantly, this categorization was found to be supported by a number of measures of face-to-face lecture attendance and RLV usage (see Table 1). In particular, significant differences at the .01 level were found between low and regular RLV users by using staff-logged, computer-logged and student self-report of lecture attendance/viewing. For example, the low video usage group was found, overall, to be significantly more reliant upon face-to-face lectures than the regular video usage group $(\mathrm{p}=$ 0.009). Third, such a categorization is consistent with prior research suggesting undergraduate mathematics students are more likely to rely on one learning resource (or none) rather than establishing a "blended" learning environment [32].

$<$ Table 1 about here $>$

This split produced two groups of 15 students, with the low RLV users being those who viewed only 0 to 9 (including four students who never accessed any videos) RLVs over the duration of the course and the regular users those who viewed 10 to 77 RLVs over the duration of the course. As shown in Table 2, with both groups consisting of 14 males and one female, regular RLV users were found to be significantly older than low users (on average, almost four years; $\mathrm{p}=0.013$ ). Importantly, based on the pre-test scores of the two groups, no significant differences were found in either prior knowledge in mathematics, initial measures of approaches to studying or prior experience using RLVs.

$<$ Table 2 about here $>$

Following this, as shown in Table 3, paired t-tests were conducted to investigate for significant differences in pre- and post-test measures of approaches to studying and conceptions of mathematics (two tests per group or four overall). One significant difference was found in approach measures for the regular use group. This was for SA measures: A paired t-test indicated that regular RLV users post-test SA measures were significantly higher $(M=23.73, S D=7.06)$ than their pre-test SA measures $(M=21.47, S D=5.68), t(14)=-2.605, p=0.021, d=0.38$.

$<$ Table 3 about here $>$

\section{Phase 2: UK Study}

Students' ( $\mathrm{n}=63$ ) total RLV views are displayed in Figure 2, with total views ranging from 0 to 46 per student. No overall correlation was found between final course grade and RLV views.

$<$ Figure 2 about here $>$

UK students' approaches to learning: low vs. regular RLV users 
As with the Australian analysis, low users were separated from regular users by splitting the median. Also similar, significant differences were found between low and regular RLV users by using staff-logged, computer-logged and student self-report of lecture attendance/viewing, with no significant difference in tutorial usage (see Table 4).

$<$ Table 4 about here $>$

This split produced two groups: 32 low users and 31 regular users, with an even split occurring with those accessing RLV's four times (i.e. 0 to 4 views for low users and 4 to 46 views for regular users; including fourteen students who never accessed any videos). For prior knowledge of mathematics, the previous mathematics course grade indicated that regular users had significantly, but marginally, better prior knowledge of mathematics $(p=0.003)$. No significant difference between groups was found for any of the approach measures. Both groups had a near identical gender split (Low: 5 females/27 males; Regular: 5 females/26 males). Age data was unavailable, however, it was well known, as this lecturer confirmed, that students were generally all the same age, having commenced their engineering degree program directly upon completion of their secondary schooling.

$<$ Table 5 about here $>$

Finally, as shown in Table 6, paired t-tests were conducted to investigate for significant differences in pre- and posttest measures of approaches. Again, one significant difference was found in approach measures. This was again for the SA measures of the regular use group: A paired t-test indicated that regular RLV users post-test SA measures were significantly higher $(M=25.48, S D=6.93)$ than their pre-test SA measures $(M=23.58, S D=6.62), t(30)=-2.771$, $p=.010, d=0.42$.

$<$ Table 6 about here $>$

In summary, for both study phases, low and regular RLV users did not differ significantly in their practical/tutorial usage but low users were found to attend significantly more live lectures than regular users. In this context, from course start to finish, both Australian and UK regular RLV users, overall, significantly increased their SA measures. This occurred while low users displayed no significant changes. These results will now be discussed.

\section{Discussion}

For the Australian context, as shown in Table 3, SA measures increased significantly for the regular RLV users. With all but age and lecture usage being equal, this suggests the use of RLVs, in the context of reduced live lecture attendance, may somehow be enabling these students to adopt a more surface approach to learning. Yet such findings may come as little surprise. The older age of the regular RLV users may, for example, suggest these students are more time pressed, with work and family responsibilities on top of their engineering studies - a degree program many consider to have a demanding course workload [62]. For these students, the RLVs may be the principle means through which they make sense of the mathematics being taught. These students may lack a deeper intrinsic motivation to understand the course content and have less opportunities to interact with peers or the lecturer (e.g., to clarify any misunderstandings). In short, they may be more likely to resort to memorizing rather than understanding what they are learning. For such students, if they are searching for the most efficient means of learning the course content, they may unwittingly be using a less efficient means. Such a dynamic is consistent with prior research which has found learner perception of the benefit of some activity does not always match reality [61].

For the UK context, as shown in Table 6, SA measures also increased significantly for regular RLV users. However, unlike the Australian participants, when comparing low and regular RLV users, no age differences were considered to exist and regular users were found to have marginally, but significantly, better prior knowledge of mathematics. There is some complexity here that requires further research. Yet, current findings from both phases suggest a reduction in live lecture attendance coupled with a dependence on RLVs is somehow enabling these students to adopt a more surface approach to learning. Moreover, this appears to be in the context of similar practical/tutorial usage, as regular users were found to have only marginally, and not significantly, lower practical/tutorial attendance than low users.

While lending some support to Le et al.'s [20] hypothesis associating some RLV use with surface approaches to learning, these findings also help explain some of the negative correlation between RLV use and academic performance: Specifically, they provide evidence to suggest the known negative correlation between RLV use and 
academic performance in mathematics courses is not simply because weaker students tend to rely more heavily on RLVs [23]: In so far as approaches to studying are associated with the quality of learning [51,52], findings from this study provide some evidence to suggest that regular RLV use, overall, may be depressing the quality of student learning.

Returning to the characterization of cognitive engagement as the extent of active involvement in an activity (i.e. a quantitative measure) together with the nature of this involvement [i.e. a qualitative measure; see 39]. The ubiquity and ongoing advancement of computer hardware, software and internet access provide what may perhaps be considered an unprecedented means for students to access course content via RLVs accessible online. Many students may choose to forego live face-to-face lectures given the viewing of RLVs, at least on the surface, may appear to provide a near equivalent learning experience. Many may in fact do so repeatedly, as these [and other; see 23] findings clearly suggest. In one sense, this may appear advantageous given the extent to which many students may be cognitively, or otherwise, engaging with the mathematics. Yet, the present findings would appear to suggest more is not always better. In fact, these findings suggest, overall, those regularly using RLVs may be developing cognitive engagement strategies known to be at odds with deeper learning. Here it is appropriate to highlight recent arguments that face-to-face lecturing continues to "have substantial merit", particularly in mathematics [67, p.3], and further suggest a few reasons why.

In particular, where RLVs present a purely one-way form of interaction (lecturer $\rightarrow$ student), to some greater or lesser extent all face-to-face lectures are two-way (lecturer $\leftrightarrow$ student). This may be hard to discern in some courses where, for example, the lecturer simply reads from prepared notes or a series of PowerPoints. Yet even in these cases there is at least some tacit acknowledgement of the "other" in the room. This may manifest itself in subtle and overt interactions such as, for example, reading and responding to perceived restlessness, changes in eye gaze [68] or the use of gestures [69]. Even changes in tone of voice or the use of silence have been recognised as other means of interacting [70]. And where the lecturer is more interactive, two-way interactivity may be more overtly manifested in changes of direction in the way the instruction is played out.

The lecturers for both courses used in this study were interactive. For example, some lecture time was spent posing questions and providing feedback. Yet RLVs, at least those most commonly used at present, generally present no such two-way interactivity. Instead student sense-making is under the complete control of the student: Generally, they determine how they will learn using the RLVs and when that learning has been achieved. On the surface this more "student-centred" approach may appear desirable, even advantageous, yet the present findings may suggest there are limits to some student-led learning. To be sure, this would appear to be the case when we contrast the one-way interactivity described above with the reflective interactivity associated with developing students' deep understanding of mathematics [71,72]. As Skemp [73] conjectured, higher-level thinking in mathematics appears to be encouraged by an alternation between reflection and discussion. Indeed, in the context of learner engagement with RLVs, a natural corollary may be that the same content, presented the same way, viewed repeatedly and with no alternation with discussion facilitates a more surface level reflection leading to a poorer understanding of the associated mathematics. As may be foreseen, one way to avoid this dynamic may be to integrate a carefully designed interactive component into each RLV [74]. For example, at carefully selected junctures in the RLV students may be prompted to complete conceptually-focused tasks which will be peer assessed $[75,76]$.

There are limitations to this study and immediate generalizability is cautioned, particularly given the non-random method of data collection ${ }^{6}$ and the specific engineering mathematics context. Several questions remain: First, how are regular users actually using RLVs to learn? The present study provides some quantitative findings. We suggest a follow-up qualitative study would better inform the design and use of RLVs in mathematics. In particular, as discussed earlier, we do not control for all possible factors influencing these outcomes. As a question for further research, how, for example, do environmental factors associated with RLV use contribute to the development of surface approaches to learning? Second, what is the potential that perceptible negative effects of regular RLV use in a single course may be amplified and/or solidified over several courses or an entire program of study? Third, relatedly, the pedagogical implications of this study for a flipped learning teaching approach would appear important. Does this effect play out in a flipped learning context? Fourth, would we find a similar effect with, for example, short

\footnotetext{
${ }^{6}$ Not to mention differences in the two course contexts in regards to the level of mathematics covered and the number of lectures overall.
} 
staged videos covering specific concepts [e.g., screencasts; 5, 77]? In summary, more broadly, what are the best practices for the use of RLVs and recorded videos in general, and in mathematics specifically?

\section{Conclusion}

How does regular use of RLVs in mathematics affect students' cognitive engagement in learning mathematics? This was the primary question asked in this study. Cognitive engagement was operationalized using the Revised Approaches to Studying (R-SPQ-2F) questionnaire and pre- and post-test comparisons were made between low and regular RLV users in two study contexts, in Australia and the UK.

Findings suggest a reduction in live lecture attendance coupled with a reliance on RLVs for sense making in mathematics is enabling students, overall, to develop more surface approaches to learning. In consideration of prior research, where RLV use, overall, was found to be negatively correlated with academic performance, these findings provide some empirical evidence that regular RLV use may be adversely affecting student academic performance because they enable students to adopt more surface approaches to learning mathematics.

Future research is needed, both to replicate these findings and answer those further related questions detailed above. In the interim, given the growing reliance on RLVs in current pedagogical innovations (e.g., flipped learning), we suggest this study has important implications for future pedagogical development and adds to the sense of urgency regarding research into best practices using RLVs and recorded videos, in general, in mathematics.

\section{Acknowledgements}

This research was made possible through a Division Research Performance Fund grant awarded at the University of South Australia. 


\section{References}

1 Miles CA. Strong and increasing demand for lecture capture in the changing Australian university classroom: results of a national and institutional survey. In: Reiners T, von Konsky BR, Gibson D, et al., editors. Globally connected, digitally enabled. Proceedings of ASCILITE; 2015 Nov 29-Dec 2; Perth, Australia. p. 204-211.

McGarr O. A review of podcasting in higher education: Its influence on the traditional lecture. Australasian Journal of Educational Technology. 2009;25(3):309-321.

3 Australian Education Network. [Internet]. Australian University Rankings [cited 2018 Feb 28]. Available from: http://www.australianuniversities.com.au/rankings/\#rankingsoverview

Sankey M. Lecture capture in Australasian universities: A Report by the Academic Services Division of the University of Southern Queensland on behalf of the Australasian Council on Open, Distance and e-Learning: Toowoomba, Australia: University of Southern Queensland; 2013.

Dunn PK, McDonald C, Loch B. StatsCasts: Screencasts for complementing lectures in statistics classes. International Journal of Mathematical Education in Science and Technology. 2015;46(4)521-532.

Davis SJ, Connolly A, Linfield E. Lecture capture: making the most of face to face learning. Engineering Education: Journal of the Higher Education Academy Engineering Subject Centre. 2009;4,4-13.

Green KC. The 2010 Campus Computing Survey [Internet]. 2014 Jan 29 [cited 2017 Oct 12]. Available from: http://www.itcnetwork.org/component/content/article/48-library-articles-abstractsresearch/297-2010campus-computing-survey.pdf

Craig P, Wozniak H, Hyde S, et al. Student use of web based lecture technologies in blended learning: Do these reflect study patterns. In Atkinson, RJ. McBeath, C, editors. Same Places, Different Spaces. Proceedings of ASCILITE; 2009 Dec 6-9; Auckland, NZ. p. 158-167.

Larkin HE. 'But they won't come to lectures ...' the impact of audio recorded lectures on student experience and attendance. Australasian Journal of Educational Technology. 2010;26:238-249.

Toppin IN. Video lecture capture (VLC) system: A comparison of student versus faculty perceptions. Education and Information Technologies, 2011:16(4):383-393.

11 Signor L. An exploration into the reactions of undergraduate students to virtual lectures. In: Creasey S, editor. OLT Excellence: making the connections conference; 2003 Nov 3; Brisbane Queensland University of Technology. p. 125-132.

von Konsky BR, Ivins J, Gribble SJ. Lecture attendance and web based lecture technologies: A comparison of student perceptions and usage patterns. Australasian Journal of Educational Technology. 2009;25(4):581595.

Bassili JN, Joordens S. Media player tool use, satisfaction with online lectures and examination performance. Journal of Distance Education. 2008;22:93-107.

14 Cramer KM, Collins KR, Snider D, et al. The virtual lecture hall: Utilisation, effectiveness and student perceptions. British Journal of Educational Technology. 2007;38(1):106-115.

Grabe M, Christopherson K. Optional student use of online lecture resources: Resource preferences, performance and lecture attendance. Journal of Computer Assisted Learning. 2008;24(1):1-10.

Wieling MB, Hofman WH. The impact of online video lecture recordings and automated feedback on student performance. Computers \& Education. 2009;54:992-998.

Edirisingha P, Fothergill J. Balancing e-lectures with podcasts: a case study of an undergraduate engineering module. Engineering Education: Journal of the Higher Education Academy Engineering Subject Centre. 2009;4:14-24.

Ross TK, Bell PD. 'No significant difference' only on the surface. International Journal of Instructional Technology and Distance Learning. 2007;4:3-13.

19 Folley D. The lecture is dead long live the e-lecture. Electronic Journal of E-Learning, 2010;8:93-100.

20 Le A, Joordens S, Chrysostomou S, et al. Online lecture accessibility and its influence on performance in skills-based courses. Computers \& Education. 2010;55:313-319.

21 Kushnir PL, Berry K, Wyman J, et al. Lecture Capture: Good Student Learning or Good Bedtime Story? An Interdisciplinary Assessment of the Use of Podcasts in Higher Education. In: Bastiaens T, Ebner M, editors. World Conference on Educational Multimedia, Hypermedia and Telecommunications; 2011 Jun 27-Jul 1; Lisbon, Portugal. 3168-3178. 
Leadbeater W, Shuttleworth T, Couperthwaite J, et al. Evaluating the use and impact of lecture recording in undergraduates: Evidence for distinct approaches by different groups of students. Computers \& Education. 2013;61:185-192.

23 Trenholm S, Alcock L, Robinson CL. Mathematics lecturing in the digital age. International Journal of Mathematical Education in Science and Technology. 2012;43(6):703-716.

24 Moss ND. Podcasting of lectures: Learning from download statistics. In: Proceedings of the 3rd International Pedagogies and Learning Conference; 2007 Sep 27-28; Springfield, Queensland.

25 Traphagan T, Kucsera JV, Kishi K. Impact of class lecture webcasting on attendance and learning. Educational Technology Research and Development. 2010;58(1):19-37.

Chiu PS, Chen HC, Huang YM, et al. A video annotation learning approach to improve the effects of video learning. Innovations in Education and Teaching International, 2016;1-11.

Dahlstrom E, Bichsel J. EDUCAUSE Center for Analysis and Research (ECAR) Study of Undergraduate Students and Information Technology: Research report. Louisville, CO: ECAR; 2014 Oct.

Yoon, C., Oates, G., \& Sneddon, J. Undergraduate mathematics students' reasons for attending live lectures when recordings are available. International Journal of Mathematical Education in Science and Technology. 2014:45(2), 227-240.

29 Henderson S, Broadbridge P. Engineering mathematics education in Australia. MSOR Connections. 2009;9(1):12-17.

30 Varsavsky C. Chances of success in and engagement with mathematics for students who enter university with a weak mathematics background. International Journal of Mathematical Education in Science and Technology. 2010;41(8):1037-1049.

31 Scott CE, Green LE, Etheridge DL. A comparison between flipped and lecture-based instruction in the calculus classroom. Journal of Applied Research in Higher Education. 2016;8(2):252-264. Inglis M, Palipana A, Trenholm S, et al. Individual differences in students' use of optional learning resources. Journal of Computer Assisted Learning. 2011;27(6):490-502.

33 Owston R, Lupshenyuk D, Wideman H. Lecture capture in large undergraduate classes: Student perceptions and academic performance. The Internet and Higher Education. 2011;14(4):262-268. Biggs J, Kember D, Leung DY. The revised two-factor study process questionnaire: R-SPQ-2F. British journal of educational psychology. 2001;71(1):133-149. Attard C, Ingram N, Forgasz H, et al. Mathematics education and the affective domain. In: Makar K, Dole S, Visnovska J, et al., editors. Research in Mathematics Education in Australasia 2012-2015. Singapore: Springer; 2016. p. 73-96. Watt HM, Goos M. Theoretical foundations of engagement in mathematics. Mathematics Education Research Journal, 2017; 1-10.

37 Seaton KA, King DM, Sandison CE. Flipping the maths tutorial: A tale of n departments. Gazette of the Australian Mathematical Society. 2014;41(2):99-113.

38 Naccarato E, Karakok G. Expectations and implementations of the flipped classroom model in undergraduate mathematics courses. International Journal of Mathematical Education in Science and Technology. 2015;46(7):968-978.

39 Helme S, Clarke D. Identifying cognitive engagement in the mathematics classroom. Mathematics Education Research Journal, 2001;13(2):133-153.

40 Carini RM, Kuh GD, Klein SP. Student engagement and student learning: Testing the linkages. Research in Higher Education. 2006;47(1):1-32.

41 Azevedo R. Defining and measuring engagement and learning in science: Conceptual, theoretical, methodological, and analytical issues. Educational Psychologist. 2015;50(1):84-94.

42 Fredricks JA, McColskey W. The measurement of student engagement: A comparative analysis of various methods and student self-report instruments. In: Christenson SL, Reschly AL, Wylie C, editors. Handbook of Research on Student Engagement. US: Springer; 2012. p. 763-782. Fredricks JA, Blumenfeld PC, Paris AH. School engagement: Potential of the concept, state of the evidence. Review of Educational Research. 2004;74(1):59-109.

44 Durksen TL, Way J, Bobis J, et al. Motivation and engagement in mathematics: a qualitative framework for teacher-student interactions. Mathematics Education Research Journal, 2017; 1-19. 
Skilling K, Bobis J, Martin AJ, et al. What secondary teachers think and do about student engagement in mathematics. Mathematics Education Research Journal, 2016;28(4):545-566.

Skilling K, Styliandes G. Promoting cognitive engagement in secondary mathematics classrooms. In: Krainer K, Vondrová N, editors. Proceedings of the 9th Congress of the European Society for Research in Mathematics Education; 2015 Feb 4-8; Prague, Czech Republic. 1280-1286.

Archambault I, Janosz M, Chouinard R. Teacher beliefs as predictors of adolescents' cognitive engagement and achievement in mathematics. The Journal of Educational Research. 2012;105(5):319-328.

Coupland M, Dunn PK, Galligan L, et al. Tertiary Mathematics Education. In: Makar K, Dole S, Visnovska J, et al., editors. Research in Mathematics Education in Australasia 2012-2015. Singapore: Springer; 2016. p.187-211.

Attard C, Curry C. Exploring the use of iPads to engage young students with mathematics. In: Dindyal J, Cheng LP, Ng SF, editors. Mathematics Education: Expanding Horizons. Proceedings of the 35th Annual Conference of the Mathematics Education Research Group of Australasia; 2012 Jul 2-6; Singapore. 75. Kong QP, Wong NY, Lam CC. Student engagement in mathematics: Development of instrument and validation of construct. Mathematics Education Research Journal. 2003;15(1):4-21.

Trigwell K, Prosser M. Improving the quality of student learning: the influence of learning context and student approaches to learning on learning outcomes. Higher Education. 1991;22(3):251-266.

Trigwell K, Prosser M, Ramsden P, et al. Improving student learning through a focus on the teaching context. In: Gibbs G, editor. Improving Student Learning. Oxford (UK): Oxford Centre for Staff Development; 1998. p. 97-103.

Marton F, Säljö R. On qualitative differences in learning: I. outcome and process. British Journal of Educational Psychology. 1976a;46(1):4-11.

Marton F, Säljö R. On qualitative differences in learning: II. Outcome as a function of the learner's conception of the task. British Journal of Educational Psychology. 1976b;46(2):115-127.

Biggs JB. Approaches to learning in two cultures. In: V. Bickley, editor. Teaching and learning styles within and across cultures: Implications for language pedagogy. Hong Kong: Institute for Language in Education; 1989.

Justicia F, Pichardo MC, Cano F, et al. The revised two-factor study process questionnaire (R-SPQ-2F): Exploratory and confirmatory factor analyses at item level. European Journal of Psychology of Education. 2008;23(3):355-372.

Ginns P, Ellis R. Quality in blended learning: Exploring the relationships between on-line and face-to-face teaching and learning. The Internet and Higher Education. 2007;10(1):53-64.

Cano F, Berbén ABG. University students' achievement goals and approaches to learning in mathematics. British Journal of Educational Psychology. 2009;79(1):131-153.

Murphy PE. Student Approaches to Learning, Conceptions of Mathematics, and Successful Outcomes in Learning Mathematics. In: L.N. Wood \& Y.A. Breyer (Eds.), Success in Higher Education; 2017. Singapore: Springer. p. 75-93.

Baroody AJ, Feil Y, Johnson AR. An alternative reconceptualization of procedural and conceptual knowledge. Journal for Research in Mathematics Education, 2007;38(2):115-131.

Bjork RA, Dunlosky J, Kornell N. Self-regulated learning: Beliefs, techniques, and illusions. Annual Review of Psychology. 2013;64:417-444.

Kember D, Jamieson QW, Pomfret M, et al. Learning approaches, study time and academic performance. Higher Education. 1995;29(3):329-343.

Henderson M, Selwyn N, Aston R. What works and why? Student perceptions of 'useful' digital technology in university teaching and learning. Studies in Higher Education. 2017;42(8):1567-1579.

Gliem JA, Gliem RR. Calculating, interpreting, and reporting Cronbach's alpha reliability coefficient for Likert-type scales. In: Proceedings of the 2003 Midwest Research-to-Practice Conference in Adult, Continuing, and Community Education; 2003; Columbus (Ohio): Ohio State University.

De Coster J, Gallucci M, Iselin A. Best practices for using median splits, artificial categorization, and their continuous alternatives. Journal of Experimental Psychopathology. 2011;2(2):197-209.

Thornton, B., Faires, A., Robbins, M., \& Rollins, E. The mere presence of a cell phone may be distracting. Social Psychology. 2014:45(6):479-488. 
The London Mathematical Society. Teaching Position Statement. Mathematics degrees, their teaching and assessment. [Internet]. 2017 Apr 27 [cited 2017 Oct 12]. Available from:

https://www.Ims.ac.uk/sites/lms.ac.uk/files/Mathematics/Policy_repors/2010\%20teaching_position_statemen t.pdf

68 Tall D. Cognitive conflict and the learning of mathematics. First Conference of the International Group for the Psychology of Mathematics Education. Utrecht, Netherlands. 1977. [Internet]. 2017 May 27 [cited 2017 Oct 12]. Available from: http://www.warwick.ac.uk/staff/David.Tall/pdfs/dot1977a-cog-confl-pme.pdf.

69 Roth WM. Gestures: Their role in teaching and learning. Review of Educational Research. 2001;71(3):365392.

70 Björklund Boistrup L. Assessment discourses in mathematics classrooms: A multimodal social semiotic study. [dissertation]. Stockholm (Sweden): Stockholm University Department of Mathematics and Science Education; 2010.

71 Janvier C. Constructivism and its consequences for training teachers. In: Steffe LP, Nesher P, Cobb P, et al., editors. Theories of Mathematical Learning. Mahwah (NJ): Erlbaum. p. 449-463.

72 Goodell J. Learning to teach mathematics for understanding: The role of reflection. Mathematics Teacher Education and Development. 2000;2:48-60.

73 Skemp RR. Goals of learning and qualities of understanding. Mathematics Teaching. 1979;88:44-49.

74 Singh V, Abdellahi S, Maher ML, et al. The Video Collaboratory as a Learning Environment. In: Proceedings of the 47th ACM Technical Symposium on Computing Science Education; 2016 Mar 2-5; Memphis (TN), US. 352-357.

75 Jones I, Alcock L. Peer assessment without assessment criteria. Studies in Higher Education. 2014;39(10):1774-1787.

76 Trenholm S, Alcock L, Robinson CL. The instructor experience of fully online tertiary mathematics: a challenge and an opportunity, Journal for Research in Mathematics Education. 2016;47(2):147-161.

77 Loch, B., Jordan, C. R., Lowe, T. W., \& Mestel, B. D. Do screencasts help to revise prerequisite mathematics? An investigation of student performance and perception. International Journal of Mathematical Education in Science and Technology. 2014:45(2): 256-268. 


\section{Appendix}

\section{R-SPQ-2F Questionnaire}

Instructions: This part of the questionnaire asks about your attitudes towards your mathematics studies and your usual way of studying mathematics.

Do not worry about projecting a good image. There is no right way of studying. It depends on what suits your own style and the course you are studying. It is accordingly important that you answer each question as honestly as you can. If you think your answer to a question would depend on the mathematics subject being studied, give the answer that would apply to the particular mathematics course in which you are completing this questionnaire.

Please answer each item by circling the one most appropriate response. Do not spend a long time on each item: your first reaction is probably the best one.

\section{True of me?}

$\begin{array}{lllll}\text { A } & \text { B } & \text { C } & \text { D } & \text { E }\end{array}$

Question

\begin{tabular}{|c|c|c|c|}
\hline $\begin{array}{l}\text { Never or } \\
\text { only rarely }\end{array}$ & Sometimes & $\begin{array}{l}\text { About half } \\
\text { the time }\end{array}$ & Frequently \\
\hline
\end{tabular}

1. I find that at times studying mathematics gives me a feeling of deep personal satisfaction.

that I can form my own conclusions before I am satisfied.

3. My aim is to pass the mathematics course while doing as little work as possible.

4. I only study seriously what's given out in mathematics class or in the course outlines.

5. I feel that virtually any mathematics topic can be highly interesting once I get into it.

6. I find most new mathematics topics interesting and often spend extra time trying to obtain more information about them.

7. I do not find my mathematics courses very interesting so I keep my work to the minimum.

8. I learn some mathematics by rote, going over and over them until I know them by heart even if I do not understand them.

9. I find that studying mathematics topics can at times be as exciting as a good novel or movie.

10. I test myself on important mathematics topics until I understand them completely.

11. I find I can get by in most mathematics assessments by memorising key sections rather than trying to understand them.

12. I generally restrict my mathematics studies to what is specifically set as I think it is unnecessary to do anything extra.

13. I work hard at my mathematics studies because I find the material interesting.
A

A
B

B

B

B

B

B

B

B

B

B

B

B

B
D

E

C

D

E

E

E

E

E

E

E

E

E

A

D

E

E 
14. I spend a lot of my free time finding out more about interesting mathematics topics which have been discussed in different classes.

$\begin{array}{lllll}\text { A } & \text { B } & \text { C } & \text { D } & \text { E }\end{array}$

15. I find it is not helpful to study mathematics topics in depth. It confuses and wastes time, when all you need is a passing

16. I believe that mathematics lecturers shouldn't expect students to spend significant amounts of time studying material everyone knows won't be examined.

17. I come to most mathematics classes with questions in mind that I want answered.

18. I make a point of looking at most of the suggested readings that go with the mathematics lectures.

19. I see no point in learning mathematics material which is not likely to be in the examination.

A

A
B

B

B

B

B

C

(1)

20. I find the best way to pass mathematics examinations is to try to remember answers to likely questions.

A

C D $\quad$ E

\section{Pre-test Additional Questions}

Instructions: This part of the questionnaire asks about your previous use of recorded lecture videos.

1. Have you previously used recorded lecture videos in a mathematics course?

Never Seldom Occasionally Regularly Heavily

(Circle one response only)

2. Have you previously used recorded lecture videos in any course outside of mathematics?

Never

Seldom

Occasionally

Regularly

Heavily

(Circle one response only)

\section{Post-test Additional Questions}

Instructions: This part of the questionnaire asks about how you use the recorded mathematics lecture video associated with the present course.

1. The video player contains a pause button that allows you to pause and then restart the video. How much do you use the pause button?

$\begin{array}{lllll}\text { Almost never } & \begin{array}{l}\text { Only } \\ \text { occasionally }\end{array} & \begin{array}{l}\text { About once } \\ \text { every hour of } \\ \text { lecture time }\end{array} & \begin{array}{l}\text { About two or } \\ \text { three times } \\ \text { every hour }\end{array} & \begin{array}{l}\text { More than three } \\ \text { times every } \\ \text { hour }\end{array}\end{array}$

\section{(Circle one response only)}

If you use the pause button, why do you use it?

To be able to write down everything the lecturer says

\section{(Check all that apply)}

To be able to consult the textbook while watching the lecture 
To take a break from the lecture

To read over the lecturer's notes

I do not use the pause button

Other (specify):

2. The video player contains a seek bar (a slider) that allows you to find a place in the video. How often did you use the seek bar?

$\begin{array}{lllll}\text { Almost never } & \begin{array}{l}\text { Only } \\ \text { occasionally }\end{array} & \begin{array}{l}\text { About once } \\ \text { every hour of } \\ \text { lecture time }\end{array} & \begin{array}{l}\text { About two or } \\ \text { three times } \\ \text { every hour }\end{array} & \begin{array}{l}\text { More than three } \\ \text { times every } \\ \text { hour }\end{array}\end{array}$

\section{(Circle one response only)}

If you use the seek bar, why do you use it?

To rewatch certain sections of the lecture

\section{(Check all that apply)}

To skip to a future location in the lecture

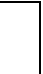

To continue watching the lecture from where you last left off

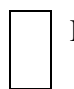

I do not use the seek bar

Other (specify):

For all remaining questions, circle 'none' or 'all lectures' or estimate (e.g. 10) the approximate number.

3. How many of the lectures did you attend in-class?

4. How many of the lectures did you watch online?

5. How many times did you attend class and watch the same lecture online (please count only classes where you watched the same material both ways for at least $30 \mathrm{~min}$ )?

6. How many times did you skip both the in-class and video lecture?
None

None

None

None
$=$ out of

All lectures

$=$ out of

All lectures out of

All lectures

$=$ out of

All lectures 


\section{Tables}

Table 1: Low vs. regular face-to-face vs. recorded video use - Australian First Year Mathematics for Engineers Course

Face-to-face attendance vs. recorded video usage (mean / median)

Low Regular

\begin{tabular}{llrc}
\hline \multirow{2}{*}{ Live Attendance } & $\begin{array}{l}\text { Practical and Tutorial }- \\
\text { Tutor/Lecturer-logged }\end{array}$ & $12.1 / 13$ & $10.7 / 12$ \\
\cline { 2 - 4 } & Lecture - Lecturer-logged ** & $19.3 / 20$ & $11.3 / 10$ \\
\hline \multirow{3}{*}{ Use of RLVs } & Computer Log or “Click” Data** & $4.27 / 3$ & $37.8 / 32$ \\
\cline { 2 - 4 } & $\begin{array}{l}\text { Student Self-Report on Post-Test } \\
* *\end{array}$ & $3.5 / 3$ & $12.3 / 12$ \\
& $\left(\right.$ out of $\left.24^{\text {b }}\right)$ & &
\end{tabular}

** Significant difference at the 0.01 level; a The course officially consisted of 26 "lectures"; ${ }^{\text {b }}$ Only the first 24 lectures are represented in this study. This was partly due to the post-test timing but also due to the final two lectures being largely for review and final exam preparation. 
Table 2: Low vs. regular video use demographic characteristics and pre-test scores - Australian First Year Mathematics for Engineers Course

\begin{tabular}{|c|c|c|c|}
\hline Initial Conditions (mean) & & Low & Regular \\
\hline Age** & & 19.2 & 23.5 \\
\hline Starting GPA & & 5.4 & 4.9 \\
\hline Previous Mathematics Course ${ }^{a}$ & & 2.3 & 2 \\
\hline Numeracy Test Score & & 26.5 & 22.7 \\
\hline \multirow{2}{*}{ Approaches to Studying Subscales } & Deep & 29.5 & 30.3 \\
\hline & Surface & 21.7 & 21.5 \\
\hline \multirow{2}{*}{ Prior experience using RLVs ${ }^{\text {b }}$} & Maths & 3 & 3.6 \\
\hline & General & 3.1 & 3.4 \\
\hline
\end{tabular}

** Significant difference at the 0.01 level; ${ }^{a}$ Available grade data was coded as $\mathrm{F} 1 / 2=0, \mathrm{P} 2=1, \mathrm{P} 1=2, \mathrm{C}=3, \mathrm{D}=4$ and $\mathrm{HD}=5$; ${ }^{\mathrm{b}}$ Experience using RLVs used the following scale: Never=1, Seldom=2, Occasionally=3, Regularly=4, Heavily=5; All figures rounded to one decimal point. 
Table 3: Low vs. regular video use pre/post-test differences in approaches to studying and conceptions of mathematics - Australian First Year Mathematics for Engineers Course

\begin{tabular}{llllll}
\multirow{2}{*}{ Instrument measures (mean) } & & \multicolumn{2}{c}{ Low Use } & \multicolumn{2}{c}{ Regular Use } \\
\cline { 2 - 6 } Approaches to Studying Subscales & & Pre & Post & Pre & Post \\
\hline \multirow{2}{*}{ Deep } & 29.5 & 31.1 & 30.3 & 29.3 \\
\cline { 2 - 6 } & Surface & 21.7 & 21.7 & $21.5^{*}$ & $23.7^{*}$
\end{tabular}

* Significant difference at the 0.05 level; All figures rounded to one decimal point. 
Table 4: Low vs. regular live vs. recorded video use - UK Second Year Mathematics for Engineers Module

Live attendance vs. recorded video usage (mean / median)

Low

Regular

\begin{tabular}{|c|c|c|c|}
\hline \multirow{2}{*}{ Live Attendance } & Tutorial - Tutor/Lecturer-Logged & $5.4 / 6$ & $4.8 / 5$ \\
\hline & Lecture - Student Self-Report ${ }^{\mathrm{a}} *$ & $20.6 / 22$ & $18.4 / 20$ \\
\hline \multirow{2}{*}{ Use of RLVs ${ }^{\mathrm{b}}$} & Computer Log or “Click” Data ** & $1.2 / 1$ & $16.3 / 11$ \\
\hline & $\begin{array}{l}\text { Student Self-Report on Post-Test** } \\
\text { (out of } 24 \text { ) }\end{array}$ & $4.2 / 3$ & $9 / 9$ \\
\hline
\end{tabular}

a The course officially consisted of 24 lectures. Lecture attendance was not recorded by the lecturer but is recorded here as what students reported for one of the post-test questions. Records available for only 7 of the 11 tutorials, with one a test and the remaining records missing; ${ }^{\text {b }}$ The discrepancy between log and self-report data may be due to system log protocols and the timing of the questionnaire administration. For example, low RLV users may be reporting having accessed the RLV system but not actually watching anything. For regular RLV users, the discrepancy may be due to the fact that the questionnaire was administered before the final exam, where RLV use is expected to increase; * Significant difference at the 0.05 level; ** Significant difference at the 0.01 level 
Table 5: Low vs. regular video use demographic characteristics and pre-test scores - UK Second Year Mathematics for Engineers Module

Initial Conditions ${ }^{\text {a }}$ (mean)

Low

Regular

Previous Mathematics Course Grade ${ }^{\text {b }}$

68.6

$70.5^{* *}$

Approaches to Studying Subscales

\begin{tabular}{lcc} 
Deep & 27.4 & 27.6 \\
\hline Surface & 22.9 & 23.6
\end{tabular}

${ }^{a}$ Based on available data. Though age data was unavailable, as the lecturer has stated, the student demographic for the engineering program at this university is almost entirely made up of students who have commenced their degree directly after completion of their secondary schooling.

This is to say that she expects no significant difference in age between low and regular use groups; ${ }^{\mathrm{b}}$ For Engineering Mathematics 2;

** Significant difference at the 0.01 level. 
Table 6: Low vs. regular video use pre/post-test differences in approaches to studying and conceptions of mathematics - UK Second Year Mathematics for Engineers Module

\begin{tabular}{|c|c|c|c|c|c|}
\hline \multirow{2}{*}{ Instrument measures (mean) } & & \multicolumn{2}{|c|}{ Low Use } & \multicolumn{2}{|c|}{ Regular Use } \\
\hline & & Pre & Post & Pre & Post \\
\hline \multirow{2}{*}{ Approaches to Studying Subscales } & Deep & 27.4 & 27.4 & 27.6 & 27.0 \\
\hline & Surface & 22.9 & 22.2 & $23.6^{*}=$ & $25.5^{*}$ \\
\hline
\end{tabular}

** Significant difference at the 0.01 level; All figures rounded to one decimal point. 
Figures

Figure 1: Australian students’ RLV views as logged by the video management system

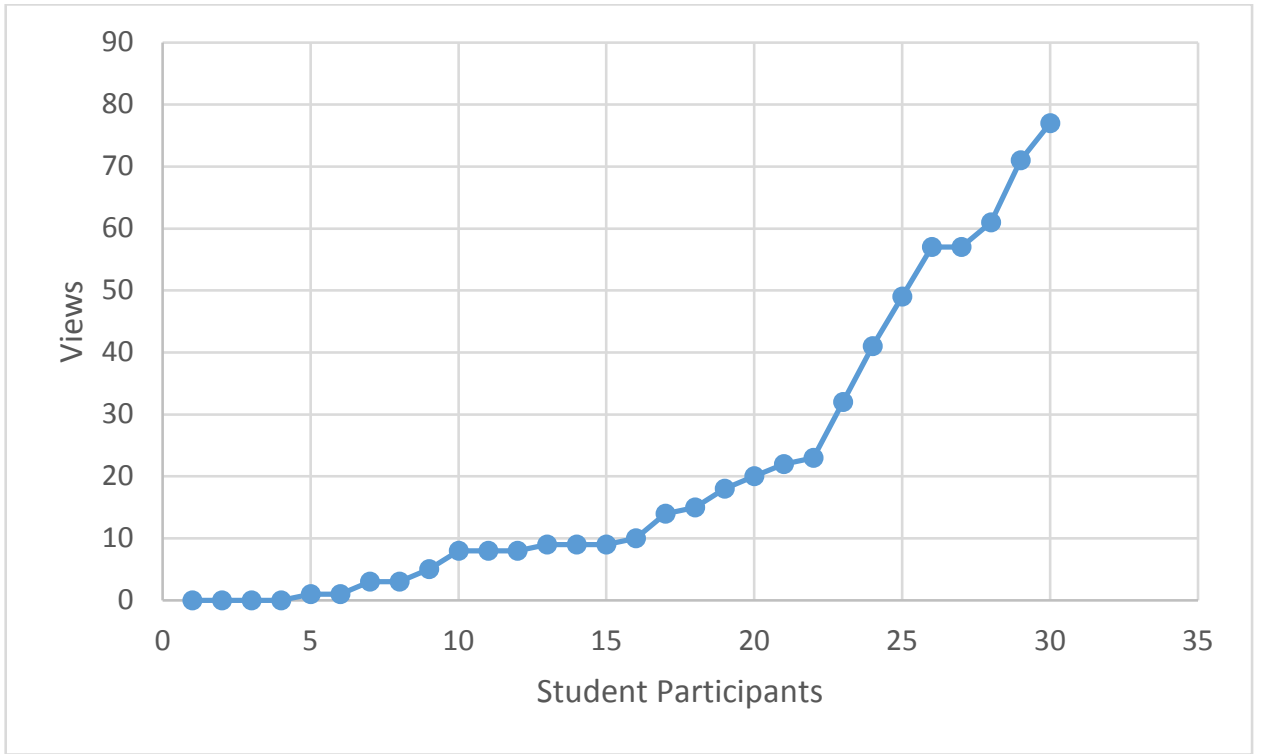


Figure 2: UK students' RLV views as logged by the video management system

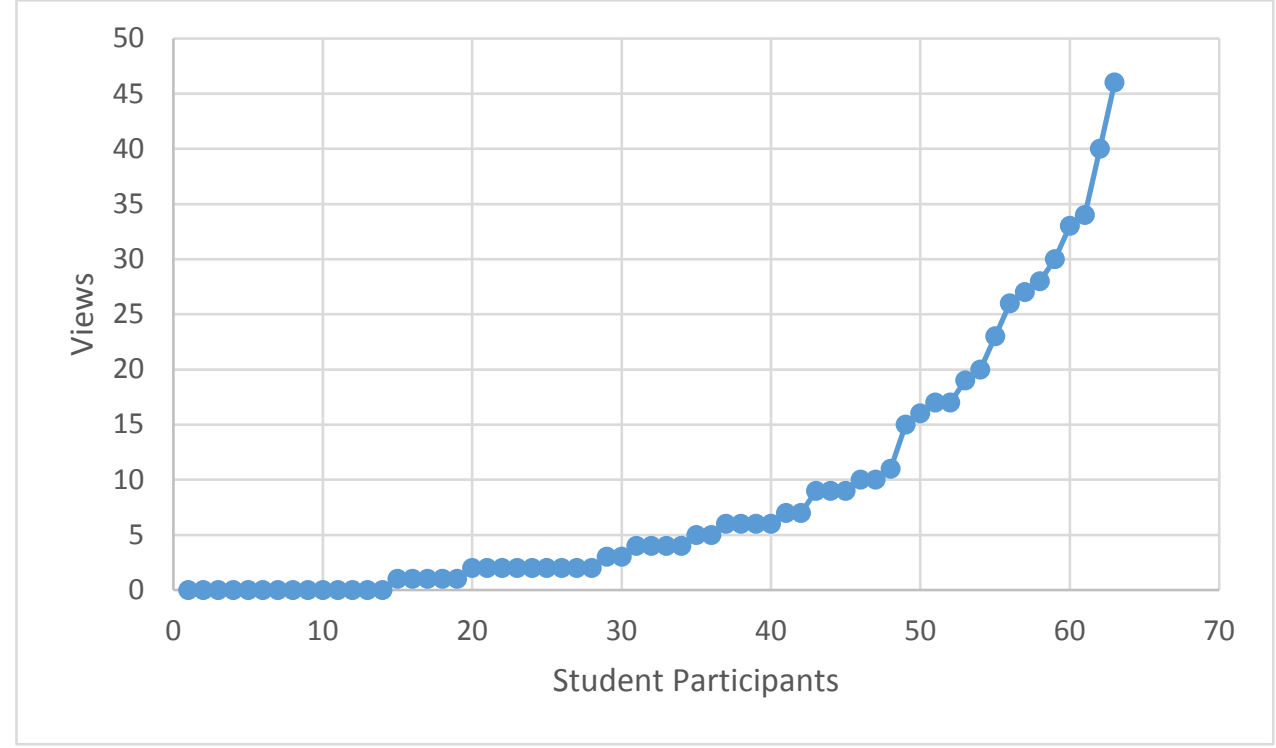

